\section{Peer observation and review improves university science teaching}

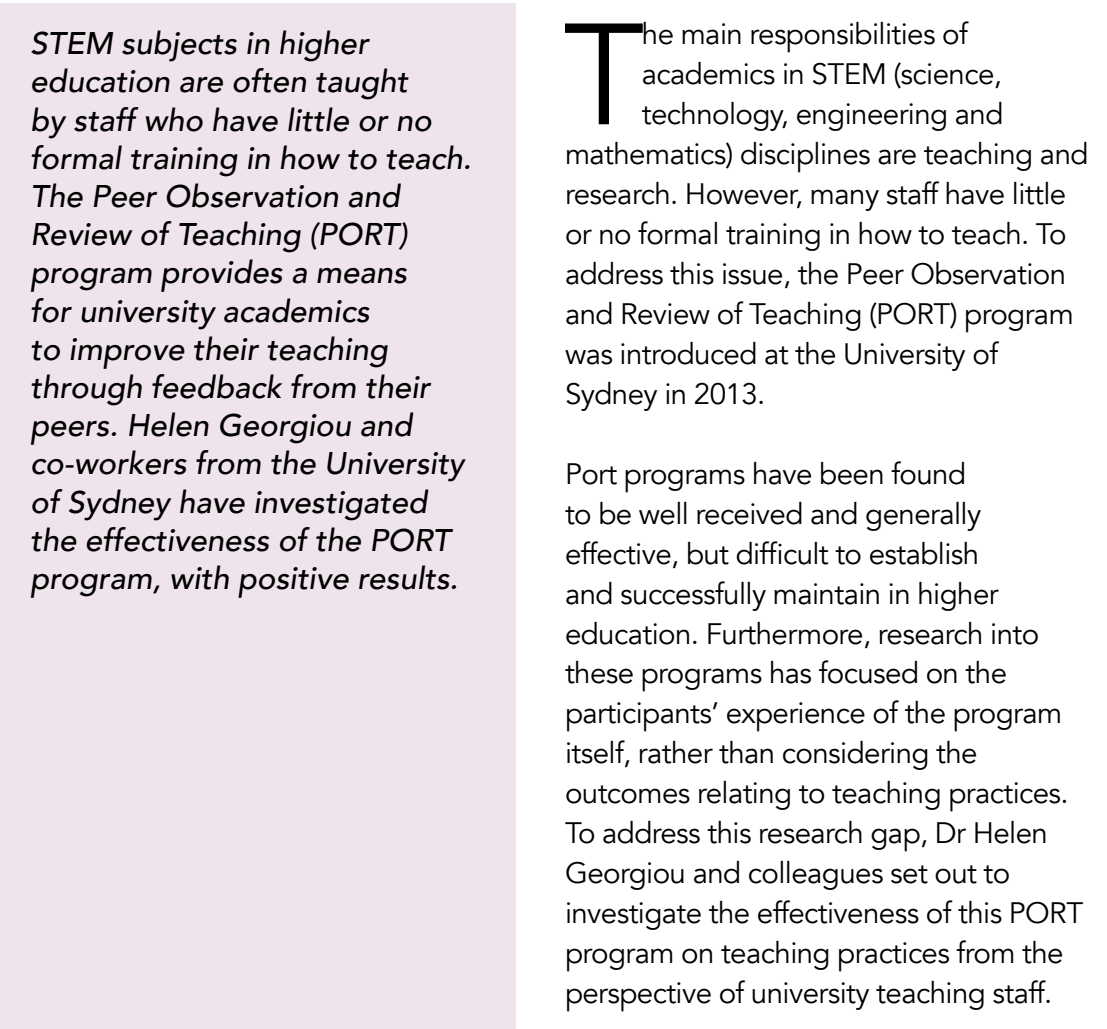

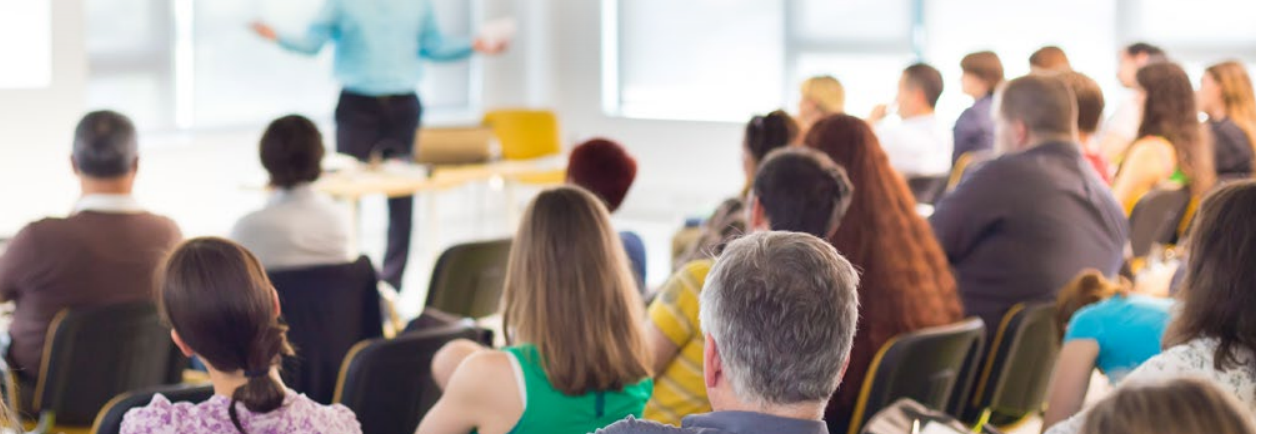

ude established professors as we s academics at the beginning of their careers.

The program begins with an initial workshop, where staff, collaborating with each oth rand the workhop faclltators, foring

Following the workshop, participants re observed whilst teaching students another academic (called the reviewer). This reviewer is a more experienced teacher with both expertise in teaching methods and in the broad discipline area. The participant and the reviewer have a follow-up meeting to discuss how the lesson went and to agree upon possible improvements using a new teaching method

The same reviewer observes the participant give a second lesson using The success of the new approch is Theviewed in a the new approach is wer direction of their teaching practice with the reviewer.

PORT participants are also encouraged to learn from their peers by observing at least two teaching sessions selected for observation because they include specific teaching methods. They are directed to critically reflect upon what they have seen using a specially designed form, Earted the Engagement (LASE) form.

At the final colloquium, participants meet to share their experiences. This has the added intention of enabling the participants to feel that they are part of

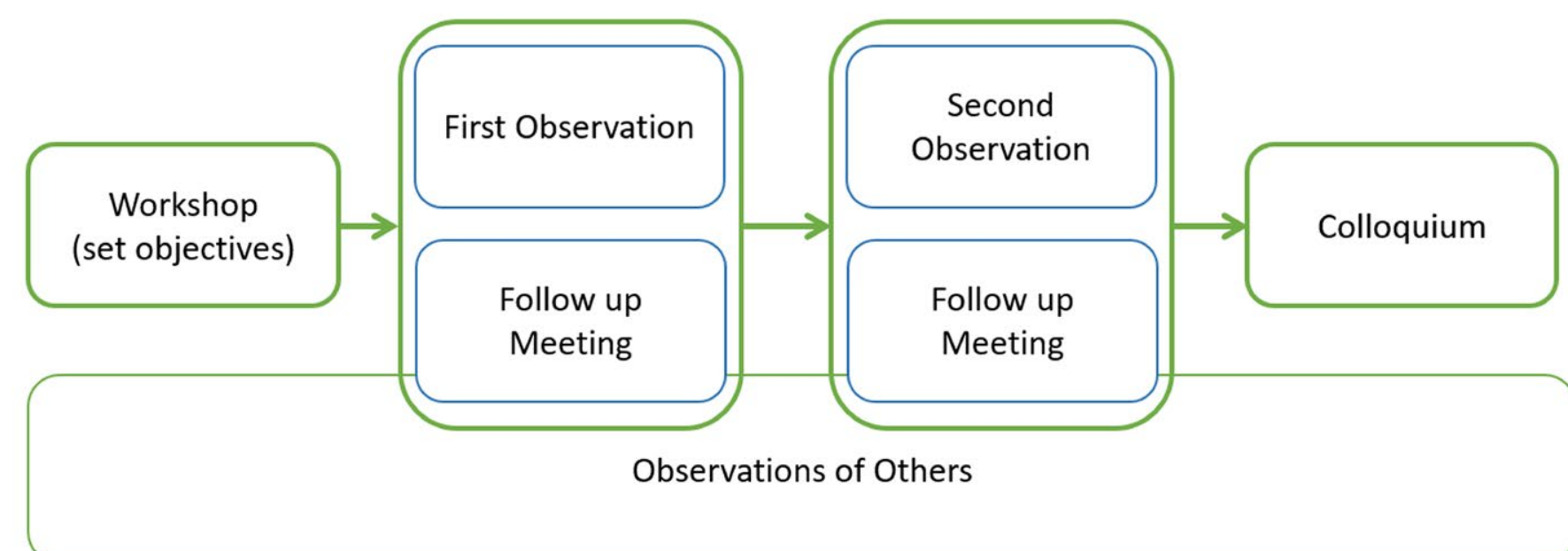

The structure of the PORT program, from the initial workshop to the concluding colloquium.

\section{RESEARCH OUESTIONS}

The researchers wanted to evaluate the impact of the PORT program on the Faculty of Science at the University of Sydney. Their specific research questions were: participants made to their

teaching practices Academ as a result of engagement in the PORT

program?

2. Were these

changes sustained aftere

3. Which elements of the pr

Which elements of the program changes?

A total of forty-three out of forty-five A ademic staff who had completed the PORT program between 2014 and 2016 were invited to take part (two could not be contacted). Sixteen academics, with differing levels of seniority within the university consented to participate in the study. The researchers acknowledge that the self-selection of the participants may have biased the study results.

\section{STUDY METHODS} a 35 -item online questionnaire. Thirty of these questions were closed and different aspects of the PORT prog as follows:
1. What, if any, are the changes the

The participating academics completed five questions permitted open-ended
- Demographics and context (Q1-Q5) two open-ended questions) - The review process/cycle (Q19-028 including two open-ended questions - Experience of the final colloquium (Q29-Q30) - Peer obserop experience (Q6-O8)

class. They appreciated the structured though some participants found the final colloquium to be less usefu.

The researchers found that all of the new teaching
methods as a res methods as a result
of participating in ectures to allow time for this active the PORT program. learning to take place. involved some form of 'active learning' by the students, such as problem solving or taking part in scientific discussions. their lectures to allow time for this ther lectures to allow the for this participant stated:

I'm teaching next semester [and I'm planning tol put a little more materia online and get them to do some pre-readings and those sorts of things and then spend more time going over detailed stuff in the lecture rather than try to cram it all.

These active learning approaches focused on meeting the needs of students. For example, one academic reduced time spent lecturing and instead gave students the opportunity to work through examples.

This change in teaching methods has improved student engagement in valued the different program, and

\section{THE FINDINGS}

Participants considered the PORT program successful at improving the engagement of their students in 
Results from PORT survey

My trial of a new strategy in my teaching was successful $(n=15)$

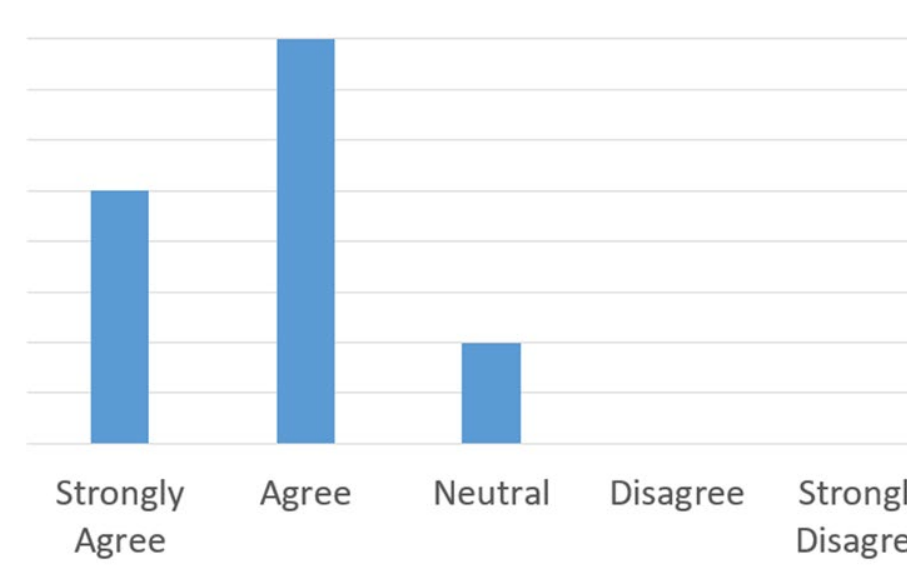

Results showing the positive response following the PORT program.

The researchers observed that the different themes identified in the PORT program all function to enhance the students" experience of learning.

I was sitting at the back of the lecture The researchers found (from the hall $\ldots$ and then I was observing all the questionnaire responses and as an students, like they [had] lecture notes, like interview theme) that the relationship Ion their] laptop, iPad lecture notes were between the academic and the review open and they were not involved in other was an important driving factor for the activities. Everyone was having la] laptop, introduction of new teaching methods. but they were not browsing [the] Internet

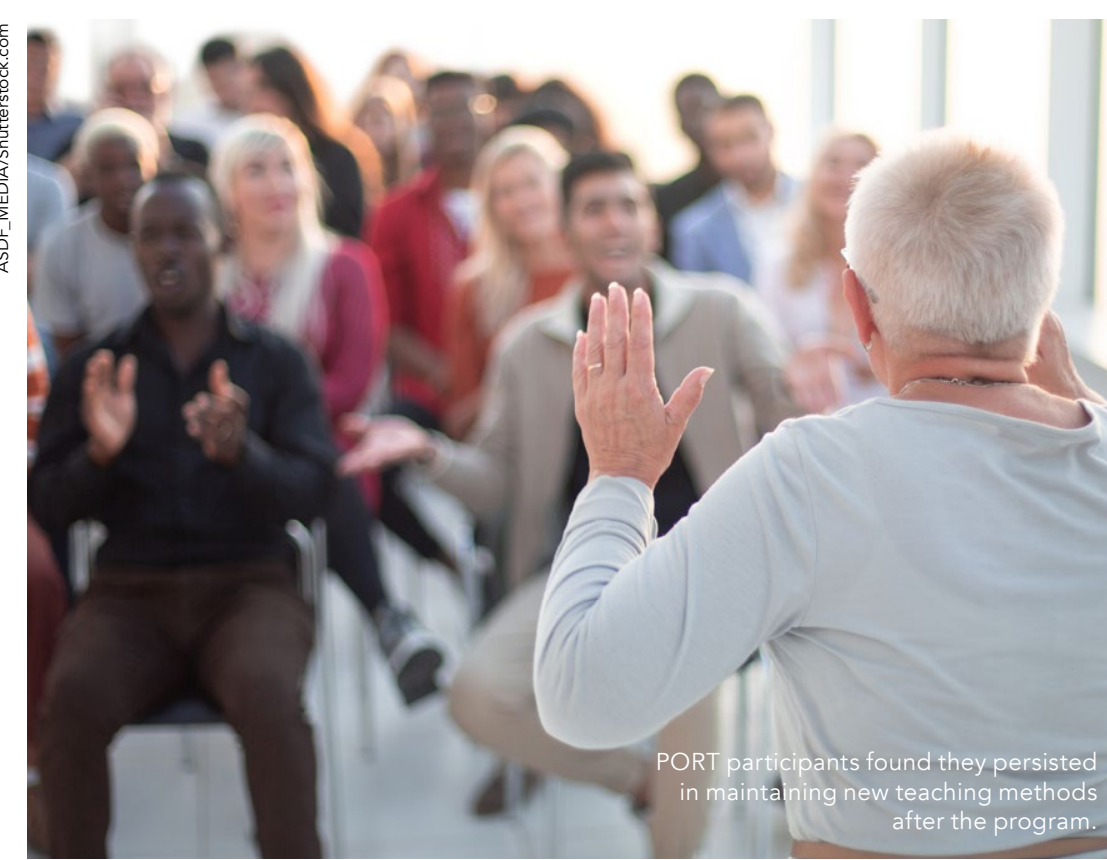

prospect. However, they valued the (eedack fom a'second pair of eyes' and tudents were responding during class.

The participants had to make decisions about which of the criticisms and iuggestions from the reviewer they vere going to take on board. They were appreciative when the reviewer had amiliarity with their discipline and could yauge how well they were explaining difficult concepts. However, they also ound that it was helpful to have a eviewer detached from their immediate vork environment. This shifted the focus sf the feedback away from the content of heir lecture and to strategies that would engage the students with the content.

The academics also benefitted from being given the opportunity to watch their peers teach. Not only did this help also helped to dispel the notion that they were 'on their own' in the lecture room. They developed a sense of being part of a university teaching community. In particular, praise from the reviewer and other peers increased their confidence.

Importantly, the PORT program

encouraged the participants to develop reflective practice, which is essential in order to sustain improvements in their teaching. Indeed, the participants have persisted in using new teaching methods and furthermore, they have recommended the PC heir colleagues.

Significantly, the researchers have observed that the different themes inction to enhan program a experience of learning.

Overall, the researchers have noted that 'legitimate and lasting' changes in teaching are difficult to achieve and they have heralded the improvements in the Faculty of Science at the University of Sydney as a transformation

\section{CONCLUSION}

Dr Helen Georgiou and co-workers from the University of Sydney have found that the PORT program has improved science teaching and studen

\section{Behind the Research}

\section{Dr Helen Georgiou}

E: helengeo@uow.edu.au 0 @contacthelen

: https://scholars.uow.edu.au/display/helen_georgiou

\section{Research Objectives}

Dr Georgiou investigates the effectiveness of the Peer Observation and Review of Teaching (PORT) program.

\section{Detai}

Helen Georgiou

University of Wollongong

Northfields Ave, 2522

Australia

Bio

Dr Helen Georgiou is a lecturer in science education at the University of Wollongong, and honorary lecturer at the University of Sydney. Her research interests include science education. She is currently working on understanding student-generated digital media, creativity in physics and peer observation and review of

Funding

fearning and Teaching (former), Australian Government

\section{Collaborators}

- Manjula D Sharma

- Graham Hendry

- Vicky Tzioumis

- Hilary Lloyd

- Diana Warren

-Asaph Widmer-Cooper

- Sharon Herkes

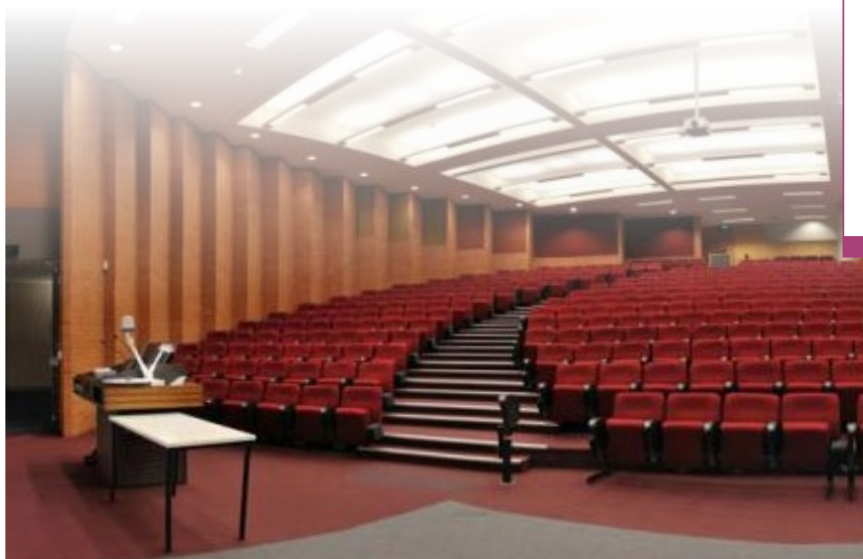

\section{References}

Hendry, G., Georgiou, H., Lloyd, H., Tzioumis, V., Herkes, S. and Sharma, M. (2021). It's hard to grow when you're stuck on your own": enhancing teaching through a peer observation and review of teaching program. International Journal for Academic Development, 26(), 54-68. Available at: https://doi.org/10.1080/1360144X.2020.1819816

Braun, V. and Clarke, V. (2006). Using thematic analysis in psychology. Qualitative Research in org/10.1191/1478088706qp063oa

\section{Personal Response}

What inspired you to conduct this research?

II The PORT program was created out of a desire development at universities, with respect to teaching Peer review is most often associated with research, but its benefits could be leveraged for the teaching program, to find out what worked and what didn't and what its impact was, in order to improve it and to share what we've learnt with the wider higher education community. Do you plan to survey university students to assess experience?

In the next phase of the research, we are analysing data from interviews with past and present reviewers. We in to understand and compare reviewer perspectives However, previous research has shown that students have positive experiences with the pedagogies used in this program, such as the 'active learning' pedagogies
mentioned earlier.

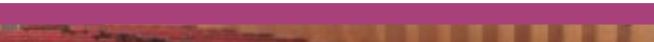

